\title{
Uma análise do poema "If recollecting were forgetting", de Emily Dickinson sob a visão de Augusto de Campos
}

\section{An analysis of the poem "If recollecting were forgetting" by Emily Dickinson from Augusto de Campos' point of view}

\author{
Benedita Teixeira Gama \\ Universidade Federal do Ceará, Fortaleza, Ceará, Brasil
}

\begin{abstract}
Resumo: Este texto propõe analisar a tradução do poema "If recollecting were forgetting" de Emily Dickinson (1830-1886) realizada pelo poeta e tradutor Augusto de Campos, buscando refletir a respeito dos caminhos percorridos pelo mesmo em seu projeto tradutório relativo à obra da poeta. Nos detemos a partir das edições de suas traduções e tomamos como base a concepção de tradução sustentada pelo movimento concretista aliado ao intuito de entender como se constrói essa prática tradutória de Augusto de Campos com a poesia dickinsoniana pelo período de mais de 30 anos.
\end{abstract}

Palavras-chave: Projeto tradutório; Crítica de tradução; Augusto de Campos; Emily Dickinson

\begin{abstract}
This paper aims to analyze the translation of the poem "If recollecting were forgetting" by Emily Dickinson (1830-1886) performed by the poet and translator Augusto de Campos, in an attempt to reflect on the paths taken by him in his translation project concerning the poet's work. We will focus on the editions of his translations and take as a basis the conception of translation supported by the concretist movement in order to understand how this translation practice of Augusto de Campos with Dickinsonian poetry is built over a period of more than 30 years.
\end{abstract}

Keywords: Translation Project; Translation Criticism; Augusto de Campos; Emily Dickinson 


\section{Considerações iniciais ${ }^{1}$}

Pode ser considerado exagerado dizer que o poeta/autor/tradutor Augusto de Campos dispensa apresentações, sobretudo em se tratando de edição/publicação nacional voltada em sua homenagem e as muitas faces que delineiam sua obra e áreas de literatura. $\mathrm{O}$ alcance merecido de suas traduções, cuja produção segue além dos círculos literários brasileiros provocam admiração e despertam interesse cada vez maiores a respeito de seu labor. É então através da análise dos esforços do tradutor/autor que chegaremos a perceber como Augusto de Campos (re) escreve Emily Dickinson nas traduções para a língua portuguesa a partir de seu projeto tradutório. Para tanto, trilharemos pelas influências do fazer literário de Augusto de Campos, considerando as soluções/escolhas tradutórias assumidas em seu projeto tradutório, bem como o modo como elas se apresentam quando confrontadas com a poética da autora.

Assumindo a provocação que a produção tradutória de Augusto de Campos nos rodeia, parte dessa tarefa diz respeito a não só ajudar a ampliar os estudos críticos acerca da poética dickinsoniana, mas também oferecer, através do trabalho do poeta-tradutor, o estímulo de um passo a mais exatamente ao considerar essas traduções como obras críticas. Analisá-la em cotejo com o texto original pode evidenciar um grau de complexidade, sobretudo, em razão dos conhecimentos teóricos de Campos. Por isso, cabe a apresentação de um breve levantamento das edições das traduções de Dickinson feitas por Augusto de Campos, de acordo com sua data e publicação, refletindo a partir da concepção de tradução sustentada pelo movimento concretista e também com o intuito de entender como se constrói essa prática tradutória de Augusto de Campos com a poesia dickinsoniana pelo período de mais de 30 anos.

As traduções dos poemas de Emily Dickinson por Augusto de Campos começaram em 1986, com a publicação de $O$ Anticrítico, obra que reúne traduções de Dante Alighieri, John Donne, Lewis Carroll e Dickinson, entre outros. A cada um desses poetas é destinada uma seção com um subtítulo relacionado à sua poesia. Augusto de Campos traduz 10 dentre os quase 1900 poemas de Dickinson, sendo assim, segundo ele, uma tradução intensiva e não extensiva.

\footnotetext{
${ }^{1}$ Este artigo faz parte da dissertação intitulada "Emily Dickinson traduzida por José Lira e Augusto de Campos".
} 
É interessante notar como essa primeira tarefa tradutória se estenderá em mais duas outras obras, pois, impulsionado pelo cuidadoso trabalho de traduzir Emily Dickinson, Augusto de Campos expande seu número de traduções para 45 poemas e lança, em 2008, a obra Emily Dickinson: não sou ninguém, ampliando assim o corpus dos 10 poemas iniciais. "I am nobody", um dos poemas mais conhecidos de Emily Dickinson, dá título ao livro, que possui uma capa mais sóbria, de fundo verde.

Nessa versão, ele segue o procedimento adotado em $O$ Anticrítico, ou seja, o poema original ocupa o lado esquerdo da página e sua tradução, o lado direito. Como os poemas não possuem títulos - uma das características de Dickinson -, o tradutor utiliza a prática de tomar como título o primeiro verso de cada poema. Outra opção interessante também adotada por Campos é a indicação do ano desses mesmos poemas, numa prática afim à edição completa dos poemas da poeta organizada por Thomas H. Johnson.

Uma segunda edição revista e ampliada das traduções da obra de Dickinson feitas por Augusto de Campos, Emily Dickinson: não sou ninguém, é publicada em 2015, também pela editora da Unicamp, composta por 80 poemas. Em nota à segunda edição, Augusto de Campos faz uma declaração reveladora. Ele afirma o seguinte: "Eu considerava já encerradas as minhas homenagens à grande poeta, feitas com muita parcimônia e cuidado, ao longo de muitos anos, com as traduções que publiquei na primeira edição deste livro" (CAMPOS apud DICKINSON, 2015, p. 13). Essa retomada às traduções de Dickinson se deve principalmente a dois importantes eventos literários: a publicação de The Gorgeous Nothings, Emily Dickinson's Envelope Poems, organizada por Jen Bervin e Marta Werner, e a publicação de seus manuscritos na internet. ${ }^{2}$

Na segunda edição de Emily Dickinson: não sou ninguém, notamos o que parece ser uma questão de ordem visual que se mostra já na capa, com destaque à imagem do manuscrito do poema original feito por Dickinson. Essa referência aponta como a questão manuscrito/original/tradução se insinua na obra dickinsoniana de modo essencial, digamos assim, através de um recurso que se relaciona aos escritos encontrados após sua morte.

A partir dessas obras, $O$ Anticrítico (1986) e as duas edições de Emily Dickinson: não sou ninguém (2008; 2015), Campos celebra a sua prática de tradução poética ao nível

\footnotetext{
${ }^{2} C f$. www.edckinson.org. Esse site disponibiliza, desde 2013, imagens de alta resolução dos manuscritos sobreviventes de Dickinson em acesso aberto, fornecendo aos leitores um arquivo web através do qual é possível ver imagens dos manuscritos guardados em múltiplas bibliotecas.
} 
exigente e criativo que lhe é de direito, atento às demandas dos "jogos vocabulares", à abordagem de temas abstratos e/ou ainda aos desafios de traduzir "[...] uma poesia densa e singular" (CAMPOS apud DICKINSON, 2015. p. 13). A extrema síntese com a qual Emily Dickinson escrevia seus poemas foi considerada uma dificuldade no embate entre as línguas inglesa e portuguesa, segundo o próprio Campos, e nesse caso a língua portuguesa pode desfavorecer, mesmo que não tão radicalmente. Reconhecida essa dificuldade, Augusto de Campos admite ter deixado de traduzir muitos poemas de Dickinson por não ter alcançado "[...] a meta de produzir poemas palatáveis em nossa língua." (CAMPOS apud KASSAB; GOMES, 2008, [s. p.]). No entanto, ele também assegura, na introdução-prefácio à edição de 2008 da coletânea Emily Dickinson: não sou ninguém, que

Tudo em Emily é paradoxo. [...] Cruzam-se em sua poesia os traços de um panteísmo espiritualizado, de uma solidão-solitude, ora serena ora desesperada, e de uma visão abismal do universo e do ser humano. Micro e macrocosmo compactados em aforismos poéticos. Da observação da natureza, em suas mais humildes manifestações, ela consegue ascender às perguntas sem resposta da vida e da morte e do amor (ainda que recessivo e sublimado) em seus epigramas-enigmas conceituais. Temas que percorreram a poesia de todos os tempos, mas assimilados aqui num idioleto de rara beleza. Sua geografia imaginária não tem limites. Frequenta os jardins do mundo. De uma borboleta do Brasil pode chegar às estrelas. Do jardim aos céus. Do som ao sonho. Do cONcRETo ao eTERNO. (CAMPOS apud DICKINSON, 2008, p. 19).

Há duas questões importantes nesse excerto: a primeira diz respeito aos temas apresentados pelo poeta-tradutor no que concerne à poesia de Dickinson; e a segunda trata de uma possível sinalização dos temas e das traduções escolhidos pelo tradutor. Considerando este mapeamento, observamos que grande parte dos poemas visa contemplar os diferentes temas apontados por Augusto de Campos no trecho acima, o que sugere tanto a sua posição tradutória de assumir a tradução como persona e de aventurarse frente à vasta obra da poeta como o seu projeto tradutório de enfatizar mediante tradução-arte uma recriação equivalente da "forma e alma" do texto original.

\section{A visão de tradução poética de Augusto de Campos}

Com base nas proposições apresentadas em prefácios e traduções elaborados por Augusto de Campos, como, por exemplo, a obra Verso Reverso Controverso, prefácio que, apesar 
de curto, aponta de modo relevante as propriedades de seu ofício como tradutor, constatamos sua identificação e afeto pelos poetas esquecidos, justificando suas traduções como forma de demonstrar esse sentimento e enfatizando sua escolha em traduzir somente aquilo de que gosta, alcançando, assim, através de suas traduções, uma seleção dos mais diversos poetas à margem do cânone, cujo objetivo principal consiste em desconstruir os julgamentos em relação à obra desses poetas.

Augusto de Campos, com efeito, ousou definir seu trabalho como tradução deglutidora na obra supramencionada, por meio da qual anuncia a ambiguidade antigo/novo e o enfrentamento/choque como referência ao conceito de antropofagia de Oswald de Andrade. Apreciador do papel inovador de Andrade no modernismo brasileiro, Campos ressalta como "[...] ele ressuscitou, nos últimos anos, para nutrir o impulso das novas gerações. Tabu até ontem, hoje totem. Nesse banquete totêmico, não devemos comemorar, mas comer a revista. Como ele queria. SOMOS ANTROPÓFAGOS." (CAMPOS, A., 2015, p. 130). Essa reflexão irreverente é justamente o traço que conectou os poetas concretos a Andrade como autor nacional e significativo, cuja provocação agitadora e habilidade de criação os poetas concretos perceberam.

Isso se torna ainda mais evidente ao analisarmos a produção crítica em que Augusto de Campos ressignifica a antropofagia de Oswald de Andrade como um banquete, recomendando a deglutição e digestão dos textos, tornando-se novos. Nas palavras do autor:

\footnotetext{
Assim como há gente que tem medo do novo, há gente que tem medo do antigo. Eu defenderei até a morte o novo por causa do antigo e até a vida o antigo por causa do novo. $\mathrm{O}$ antigo que foi novo é tão novo como o mais novo novo. $\mathrm{O}$ que é preciso é saber discerni-lo no meio das velhacas velharias que nos impingiram por tanto tempo. (CAMPOS, A., 1978, p. 7).
}

Com esse trecho, Augusto de Campos mostra o tom exigente de sua invenção, que se firma não por facilitar, mas por reatualizar, no conflito árduo de valorizar o presente e revalorizar o passado - numa ação de desenvolvimento e fortalecimento de uma língua. Não por acaso, sua concepção está pautada em ver a tradução como crítica, sendo “[...] uma das melhores formas de crítica, desde que criativa." (CAMPOS, 1978, p. 7).

A proposta de valorizar o presente e revalorizar o passado leva à seguinte indagação: como o redescobrimento da poesia provençal efetuada pelo próprio Augusto de Campos em Verso Reverso Controverso se justifica? E como o texto provençal se 
mostra ressuscitado a partir das modificações introduzidas pela tradução? Nesse quadro, a preferência pela poesia provençal tem explicação significativa nas palavras do próprio Augusto de Campos (1978, p. 8):

A poesia é uma família dispersa de náufragos bracejando no tempo e no espaço. Tento reunir aqui alguns dos seus raros sobreviventes, dos que me falam mais de perto: os que lutaram sob uma bandeira e um lema radicais - a invenção e o rigor. Os intraduzidos e os intraduzíveis. Os que alargaram o verso e o fizeram controverso, para chegar ao reverso.

E se observarmos as particularidades da poesia provençal que Augusto de Campos aprecia, em sua atividade tradutória e na sua crítica, constatamos uma natureza selecionadora, com argumentos que apresentam uma chave acertada para o que o autor destaca como "novo":

\begin{abstract}
Mas o que há de novo na poesia de Provença, a justificar a sua presença em plena era tecnológica? Há, em primeiro lugar, precisamente, a tecnologia poética, o trabalho de estruturação e de ajuste das peças do poema, em termos de artesanato, é evidente, mas que assinalam um dos mais altos momentos da poesia no sentido da apropriação do instrumento verbal e de sua adequação ao dizer poético. Só isso já bastaria para justificar a sua revivescência. (CAMPOS, 1978, p. 10).
\end{abstract}

Assumidos os riscos e o alto preço de recuperar via tradução e crítica o poema de Daniel, devemos observar o propósito destacado por Campos, o de que cabe ao tradutor não só traduzir, mas sentir o texto, "[...] dor por dor, som por som, cor por cor." (CAMPOS, A., 1978, p. 7). Ou seja, conceber na língua de chegada um texto traduzido com beleza e emoção.

Desse modo, Augusto de Campos procura justificar também a sua compreensão de tradução como crítica, guiada fortemente pela escolha e profunda identificação do tradutor com o poema a ser traduzido. Mais ainda: num sentido de que razão e emoção possibilitam cumprir uma tradução formal e entusiástica, traduzir um texto com rigor linguístico e que considere o fato de dominar o texto-fonte, para, a partir deste, conceber um novo texto que reabilite e faça conhecer de verdade o primeiro, e se transmute com autonomia em português como um belo produto. Sua prática tradutória prevê que o trabalho do tradutor deve observar atentamente o texto a ser traduzido, a fim de "[...] criar um diálogo medular com ele, captar a sua 'alma", mas "sem 'forma”,, “[...] não faz nada que preste." (CAMPOS apud DICKINSON, 2008). 
Tendo reconhecido essas dificuldades, Augusto de Campos reafirma sua técnica de que tradução é "forma e alma", ou ainda, técnica de esforço e envolvimento emocional com a poesia, e tece uma crítica a duas observações distintas: uma de ordem semântica e outra de ordem técnico-formal. A primeira, de ordem semântica, diz respeito ao enfraquecimento do conteúdo exposto a "leito de Procusto métrico" (CAMPOS apud OSEKI-DEPRÉ, 2004). A segunda, de ordem técnico-formal, é atribuída à dificuldade do tradutor em relação ao enfrentamento da dinâmica formal-emocional do texto que o caracterizava. Segundo Campos (apud OSEKI-DEPRÉ, 2004, p. 289), a possibilidade de existência dessa interpretação oferece um texto que não suporá o confronto com o original. Esse é um ponto para o qual o autor chama a atenção, destacando que há pouco conhecimento de métrica por parte dos tradutores que praticam sua atividade com textos do passado, o que ocasiona traduções com rimas pouco efetivas e sintaxe invertida, haja vista que a exigência vai além do conhecimento de métrica, pois diz respeito ao envolvimento emocional com o texto, numa proposta construtiva da linguagem, pensada a partir de um conjunto formal-semântico-emocional que deve ser observado. Para o tradutor,

É preciso muita sensibilidade para recobrar a paixão concentrada do poema, aquela "espécie de matemática inspirada" para as nossas emoções, de que fala Pound. $\mathrm{O}$ conteúdo não deve ser pensado à letra, em unidades semânticas, mas como um conjunto formal-semântico-emocional, cujo espírito deve ser captado. Algumas pequenas "traições" são inevitáveis em prol da reconstrução tradutória, o que não quer dizer que se devam desprezar os significados. Cortase aqui, recupera-se adiante. (CAMPOS apud DICKINSON, 2008, s. p.).

Nesse excerto, há a exposição desta que seria uma das questões consideradas centrais na prática tradutória de Augusto de Campos: a identificação emocional com o texto de origem. Entretanto, o fragmento também esclarece que somente essa identificação não bastaria, junto a ela é necessário associar dois outros fatores, o formal e o semântico, como fundamentais no apoio a uma interpretação carregada de beleza no idioma de chegada. A propósito, compreendemos que essa condição deve ser tomada como preceito inspirador das escolhas tradutórias dos irmãos Campos, em especial das preferências de Augusto em relação à obra de Emily Dickinson. No excerto supracitado há, ainda, uma questão concernente à tradução poética como processo tradutório, como exercício de crítica e de interpretação, ou seja, as "traições" são cometidas em nome da 
reconstrução tradutória e são inevitáveis, implicando num jogo de compensação, uma espécie de troca, por assim dizer.

Essa preocupação e atenção em perceber a tradução como tarefa desafiadora acompanham as traduções da poética de Emily Dickinson realizadas por Augusto de Campos. E mesmo após declarar seu "amor" pela poesia de Dickinson, vendo-a como carregada de síntese e essencialidade, "elíptica e aforismática", Augusto de Campos reconhece as dificuldades que surgem com a ausência de vocábulos breves na língua portuguesa que abracem com intensidade a concentração dos poemas originais. Em termos gerais, o tradutor parece optar por sacrificar muitos dos poemas com os quais se identificou, e nesse aspecto vale lembrar a questão emocional despertada nas suas escolhas, em nome do modelo de tradução-arte. Em suas palavras: "Deixei de traduzir muitos poemas dela, que me dizem muito, por não ter conseguido achar a chave, 'acertar na veia', como se diz no futebol; aí, preferi tirar o time do campo." (CAMPOS apud DICKINSON, 2008, p. 3).

\title{
3 "If recollecting were forgetting"
}

Nesta seção analisaremos o poema "If recollecting were forgetting" de Emily Dickinson e a tradução de Augusto de Campos:

\author{
If recollecting were forgetting, \\ Then I remember not, \\ And if forgetting, recollecting, \\ How near I had forgot. \\ And if to miss were merry, \\ And if to mourn were gay, \\ How very blithe the fingers \\ That gathered these Today! \\ (c. 1858) \\ (DICKINSON, 2015, p. 34)
}

Esse poema parece querer demonstrar o quanto Emily gostaria de esquecer a perda de um ente querido, em vez de recordar continuamente o acontecimento que a aflige, mas não consegue. Composto também por uma única estrofe, "If recollecting were forgetting" apresenta algo interessante a ser observado. Particularidades à parte, esse poema também apresenta mais um jogo exímio e, ao mesmo tempo, direto e simples de Dickinson, no 
qual ela deixa transparecer o que primeiro parece ser um paradoxo, tornando o ato o oposto de si mesmo, alternando tanto o jogo de palavras quanto o jogo de significado, como em uma intensa movimentação.

A chave é dada pelos pares opostos, de lembrar e esquecer, repetido e invertido, em que quase sempre um é considerado positivo, enquanto seu oposto é geralmente considerado negativo, numa percepção de que tanto o esquecimento como a lembrança implicam o seu inverso. "If recollecting were forgetting" é uma balada breve, construída em oitava, com esquema de rimas organizado nos primeiros quatro versos de forma regular, com rimas emparelhadas, $\mathrm{ABAB}$, forgetting/recollecting, not/forgot, além de uma rima interna formada pelo mesmo par de rima pobre externa do verso 1 e do verso 3. Os últimos quatro versos apresentam apenas um par de rima cruzada. Nesses mesmos versos, a poeta trabalha com aliterações e anáforas.

Esse poema apresenta uma construção respaldada na repetição, no uso de anáforas e de versos com a mesma organização sintática, resultando em uma regularidade. Contudo, é possível dividir o poema em duas partes distintas. Na primeira parte, correspondente aos quatro versos iniciais, temos duas ocorrências da conjunção condicional If, que, como o próprio nome evidencia, expressa uma ideia/posição de condição; assim, confronta as relações entre recollecting/forgetting e sustenta uma tensão entre os opostos. Nessas duas ocorrências, tem destaque a condição de uma para a outra, levando-nos a perceber, pelo menos numa primeira leitura, que se estabelecem como linhas de valor equivalente no poema. Na segunda parte do poema, esse confronto volta a acontecer, reforçado mais ainda pelo uso anafórico do conectivo And. Aqui, a poeta faz uso de adjetivos e verbos que, introduzidos a partir do quinto verso, tornam-se agentes contrastantes e resultam até mesmo numa ideia irônica - miss $=$ merry - mourn $=$ gay. $\mathrm{O}$ interessante dessa passagem é que é transmitido de forma aliterativa o jogo entre miss e merry sugerido por Dickinson, "And if to miss were merry”. A similaridade sonora desse verso é lembrada com a palavra mourn na sequência, e que Dickinson usa para caracterizar o sentir ou o expressar da tristeza. Ademais, os dois versos finais, "How very blithe the fingers / That gathered this, Today!" dá a esse confronto intenso que perpassa o poema uma função de voltar-se ao momento, como se retomasse o fio dos pensamentos conturbados, e isso é até mesmo reforçado pelo emprego da exclamação e maiusculização do advérbio Today com que se conclui o poema. 
Quanto ao ritmo e à métrica, vale destacar que Dickinson utiliza o metro de balada, ${ }^{3}$ organizando-o de maneira a se apresentar num padrão de versos em tetrâmetros nos versos ímpares e trímetros jâmbicos nos versos pares. Desse modo, o poema é construído de modo a alternar entre quatro e três pés métricos, cada pé se apresentando, então, com uma sequência entre uma sílaba átona e uma tônica. Esse ritmo se dá de forma mais acelerada na primeira parte do poema, devido à sua organização em versos tetrâmetros trocaicos. Podemos relacionar isso ao fato de o eu-lírico repisar as lembranças que já experienciou e que ainda o fazem sofrer, tendo em vista as repetições dos verbos recoletting e forgetting. Ademais, essas palavras concedem um tom de naturalidade e de simplicidade, por pertencerem a um registro informal e bastante comum da língua inglesa, embora a inquietação, a preocupação pela maneira de dizer que a poeta analisa os opostos em seus versos também se firme.

Em seguida, analisamos a versão em língua portuguesa a fim de apreciar o resultado na língua-alvo:

\section{O Anticrítico}

Se recordar fosse esquecer,

Eu não me lembraria.

Se esquecer, recordar,

Eu logo esqueceria.

Se quem perde é feliz

E contente é quem chora,

Que alegres são os dedos

Que colhem isto, Agora!

(CAMPOS, 1986, p. 112)

"If recollecting were forgetting" é sem dúvida um interessante exemplo da extrema síntese e cuidado com a linguagem que tanto Augusto de Campos admira em Dickinson. O tema da reflexão emocional ocorre por todo o poema. É possível percebêlo nos jogos vocabulares e no dilema refletido pelo eu lírico, através das repetições (recordar/esquecer) e das inversões ao longo do poema. A tradução de Campos, publicada pela primeira vez no livro $O$ Anticrítico, de 1986, manteve-se atenta aos aspectos formais do poema, como métrica, ritmo e rima. Nessa proposta tradutória, ele adota versos octossílabos e hexassílabos em correspondência ao metro da balada de Dickinson, o que

\footnotetext{
${ }^{3}$ Paulo Henriques Britto, em seu artigo "A tradução para o português do metro de balada inglês", discorre sobre a adoção do metro da balada por Emily Dickinson em toda a sua obra.
} 
mostra sua devida atenção ao uso da forma do poema-fonte como uma das grandes prioridades de seu projeto tradutório. Acerca do ritmo, a acentuação dada pelo tradutor destaca-se pela forma padronizada que permeia o poema. Em geral, o tradutor escolhe e adota a alternância entre palavras oxítonas, recordar, esquecer, feliz, e as paroxítonas, lembraria, esqueceria, contente. Essa padronização pode estar relacionada ao fato de Campos reconhecer nesse poema de Dickinson a relevância do seu ritmo e também de sua harmonia como fatores expressivos para possibilitar, inclusive, a musicalização em sua totalidade. ${ }^{4}$

Seguindo para o esquema de rimas, observamos uma leve diferença entre o original e a tradução de Campos. A estrutura apresentada por Dickinson condiz com o que é proposto pelo metro da balada, a primeira parte do poema apresenta versos com esquema de rimas em $\mathrm{ABAB}$, e na sequência $\mathrm{xCxC}$, todas perfeitas. Campos optou por elaborar um esquema de rimas $\mathrm{ABCB}$, mas manteve a rima interna com a repetição dos verbos recordar/recollecting (versos 1 e 3), e esquecer de forma invertida. Na sequência, o tradutor dá continuidade ao jogo rímico e mantém as rimas externas do poema fonte: gay/today-chora/agora. Se nos atentarmos para o efeito de suas escolhas para a primeira parte do poema, que em inglês apresenta os versos "If recollecting were forgetting, Then remember not, And if forgetting, recollecting, How near I had forgot”, e em português se apresentam como "Se recordar fosse esquecer/Eu não me lembraria/Se esquecer, recordar/ Eu logo esqueceria”, é possível notar não só um aspecto encantador em termos de musicalidade como também atestar o esmero do tradutor em recriar os aspectos formais, junto a uma sensibilidade em retomar o jogo de significados.

Nesses mesmos versos, a emoção/inquietação se faz presente na tradução de Augusto de Campos, quando ele recria a tristeza engendrada por Dickinson na construção dos jogos de palavras, empregando os opostos (recollecting/forgetting, remember/forgot), usados ainda como um recurso de repetição dos primeiros verbos. A ênfase é dada aos verbos, recollecting, como forma de usar a memória para tomar consciência (de alguma coisa ou alguém) e, forget, como algo a se deixar para trás involuntariamente, repetindoos nos versos 1 e 3 . Nesse caso, então, Campos recria esse par contrastante seguindo o mesmo padrão de repetição, porém com sua forma no infinitivo do português recordar/esquecer -, mas que está diretamente relacionado ao sentido do inglês. A escolha do tradutor pelos verbos no infinitivo segue a regra gramatical do português, pois

\footnotetext{
4 "If recollecting were forgetting" compõe a faixa número 10 de um total de 13 poemas traduzidos por Augusto de Campos e musicados por Cid Campos. Disponível em: http://www.cidcampos.com.br/sec_discografia_view.php?id=43. Acesso em: 12 nov. 2020.
} 
ambos os versos são iniciados pela conjunção condicional $S e$, fazendo uso dessa exigência.

Em outro par de verbos, remember/forgetting, a poeta aproveita a similaridade de significado do verbo remember com recollecting, mas com uma sutil diferença, pois, nesses dois verbos fica subentendido que alguém se lembrou de algo e falou sobre aquilo - a lembrança fez parte de uma conversa. Remember pode inclusive ser usado dessa forma, mas não deixa esse significado implícito, o que faz com que recollect seja um pouco mais específico. Campos verte esse par de verbos remember/forgot para o futuro do pretérito (lembraria/esqueceria) em língua portuguesa. Foi uma escolha acertada, pois conjugados dessa forma o tradutor ganhou em aspecto musical no poema.

Na segunda parte do poema, o pensamento é dado pelos termos de ausência/falha e lamentação, alternados nos versos 5 e 6 miss/mourn ("And if to miss, were merry, And to mourn, were gay”). Ambos estão semanticamente relacionados. Assim, se considerarmos também a primeira parte do poema, percebemos que Dickinson brinca com a sinonímia do par recollect/remember, dando continuidade nesses versos com os verbos mourn/merry. Ao compararmos com a tradução de Campos, percebemos que suas escolhas para esse par de verbos traduzidos por perde e chora atendem à possibilidade de ligação ao contexto semântico, embora em língua portuguesa não funcionem como sinônimo um do outro.

Para as aliterações propostas por Dickinson nesses versos - miss, merry, mourn -, Campos opta por seguir com o jogo do $\mathrm{Q} / \mathrm{C}$ das aliterações nas palavras quem (2x) e contente. Esse recurso é mantido pelo tradutor inclusive dentro do mesmo âmbito contextual do poema-fonte. Outro recurso que também se faz presente em sua tradução são as anáforas utilizadas pela poeta: And [E] usada em dois versos seguidos (5 e 6) como uma considerável forma de enfatizar a soma insistente do pensamento. Campos as utilizou, repetindo-as, no entanto, nos versos 7 e 8, vertidas para Que. O interessante desse deslocamento das anáforas feitas por Campos é que assim o tradutor faz um jogo e ganha duplamente, ou seja, além da manutenção do recurso da repetição, o uso do enjambement usado por Dickinson é preservado no poema traduzido. Portanto, nessa proposta tradutória, constatamos que Augusto de Campos alia o cuidado com os aspectos formais do poema, rimas, anáforas, aliterações e ritmo a uma sensibilidade em corresponder aos mesmos engenhos emocionais do universo do ser humano descritos por Dickinson. 


\section{Considerações finais}

Nessa amostra, Campos procura atender à variedade dos elementos importantes de sua poesia - como o ritmo, a pontuação e o uso dos travessões - são lidos/traduzidos e permanecem evidentes na sua recriação. Porém, em relação à síntese e à condensação, aspectos tão característicos da poesia dickinsoniana, Augusto de Campos mostra-se mais cuidadoso, pois, apesar de existir uma grande identificação com determinados poemas, muitos deles apresentam resistência a uma tradução emotivamente eficaz, não obtendo uma solução feliz - e para fugir dessa pressão, o tradutor declarou preferir não traduzilos.

Assim, compreendemos que nesse trabalho de Augusto de Campos como tradutor de Emily Dickinson, com efeito, o poeta/tradutor estabelece um projeto de tradução-arte, ao apresentar toda a sua experiência em torno da tradução de poesia e cumprir a tarefa de recriar a regularidade formal, sem, no entanto, provocar mudanças extremas na rede semântica dos poemas. Ademais, podemos ainda considerar que o tradutor vê na poesia de Dickinson objeto de grande substância e, também, de complexidade, e encantado pela sua poesia entrega-se à tarefa de avivá-la em português, e, mesmo "[...] não tendo a pretensão de acertar sempre”, reivindica “[...] essa espécie de liberdade” para suas “[...] interpretações tradutórias." (CAMPOS apud DICKINSON, 2015, p. 25).

Com base na análise de sua tradução e em atenção aos aspectos aqui analisados, podemos conceber o seguinte panorama: Augusto de Campos trabalha a tradução do poema de Emily Dickinson privilegiando os elementos formais. No trabalho de crítica comparativa entre o poemas e a tradução, foram preservados pelo tradutor tanto o número de estrofes e versos do original e o esquema de rimas como a pontuação, o uso dos travessões e dos substantivos capitalizados. Esse último elemento é atribuído a certas palavras para provocar um aspecto essencial dentro de sua poesia e do contexto do poema.

Outro aspecto importante diz respeito às aliterações, visto que Campos se vale de um sistema de compensações, construindo outras combinações aliterativas para que se mantenha o jogo sonoro do poema-fonte, ainda que versos à frente, mas sempre que possível dentro do mesmo campo textual. Da mesma forma, pensando a importância do significado do poema, junto ao cuidado pelas escolhas semânticas que sustentam o poema-fonte, o tradutor aproxima-se literalmente do texto dickinsoniano, por meio do uso de notáveis jogos vocabulares, jogando inclusive com uma linguagem densa sobre temas que transitam do real ao imaginário humano. Como destacamos, Augusto de 
Campos procura recriar esses jogos, mesmo sendo uma tarefa difícil, dada a complexidade em se encontrar termos semanticamente semelhantes àqueles que foram usados em inglês pela poeta e cujas provocações/intensidades também produzissem as mesmas potencialidades de sentido. Nesse processo, as compensações são fundamentais, o que é contemplado no pensamento do tradutor.

\section{Referências}

CAMPOS, Augusto de. Verso Reverso Controverso. São Paulo: Perspectiva, 1978.

CAMPOS, Augusto de. O Anticrítico. São Paulo: Companhia das Letras, 1986.

CAMPOS, Augusto de; PIGNATARI, Décio. Teoria da Poesia Concreta: textos críticos e manifestos 1950-1960. Cotia: Ateliê Editorial, 2006. p. 44-48.

CAMPOS, Augusto de. O 'vocalista' da alma e da forma. Jornal da Unicamp, Campinas, n. 417, ano XXIII, p. 5-8, 2008.

DICKINSON, Emily. Emily Dickinson: não sou ninguém. Tradução de Augusto de Campos. Campinas: Editora da Unicamp, 2008.

DICKINSON, Emily. Emily Dickinson: não sou ninguém. Tradução de Augusto de Campos. 2. ed. Campinas: Editora da Unicamp, 2015.

OSEKI-DEPRÉ, Inês. Questões sobre a tradução de "Elegy: going to bed" de John Donne. Entrevista com Augusto de Campos. In: SÜSSEKIND, Flora; GUIMARÃES, Júlio Castañon (org.). Sobre Augusto de Campos. Rio de Janeiro: 7 Letras; Fundação Casa de Rui Barbosa, 2004. p. 285-295.

SOUZA, Ana Helena. A Urdidura Subjacente: recriações de poemas de John Donne. In: SÜSSEKIND, Flora; GUIMARÃES, Júlio Castañon (org.). Sobre Augusto de Campos. Rio de Janeiro: 7 Letras: Fundação Casa de Rui Barbosa, 2004. p. 269-284

Recebido em: 23 de setembro de 2021 Aceito em: 01 de dezembro de 2021 Publicado em dezembro de 2021

Benedita Teixeira Gama

E-mail: benegama@hotmail.com

ORCiD: https://orcid.org/0000-0001-7656-1099 